\title{
LAS IMPLICACIONES REGIONALES DE LA REFORMA CONSTITUCIONAL DE LOS HIDROGARBUROS EN EL GOCE Y EJERGICIO DEL DERECHO FUNDAMENTAL AL MEDIO AMBIENTE SANO
}

\author{
THE REGIONAL IMPLICATIONS OF THE CONSTITUTIONAL RE- \\ FORM OF HYDROCARBONS IN THE ENJOYMENT AND EXERCISE \\ OF THE FUNDAMENTAL RIGHT TO A HEALTHY ENVIRONMENT
}

\author{
Enoc Alejandro García RIVERA*
}

RESUMEN: El gobierno mexicano promulgó el 20 de diciembre de 2013, una reforma constitucional encaminada a acrecentar la explotación de los hidrocarburos nacionales con el objetivo de garantizar, entre otras cosas, el suministro energético del país para las próximas décadas. Dicha reforma no sólo ha entrañado la posibilidad de obtener mayor recurso hidrocarburífero mediante la nueva forma jurídica de su explotación, sino también una mayor probabilidad de generar un impacto negativo sobre los bienes jurídicos que el derecho humano a un medio ambiente sano tutela. Por lo anterior, el presente trabajo tiene como finalidad exponer los posibles impactos que el cambio constitucional provocaría en la esfera jurídica ambiental
ABSTRACT: On December 20, 2013, the Mexican government enacted a constitutional reform aimed at increasing the exploitation of national hydrocarbons in order to guarantee, inter alia, the country's energy supply for the coming decades. This reform has not only entailed the possibility of obtaining a greater hydrocarbon resource through the new legal form of exploitation, but also a greater probability of generating a negative impact on legal rights than the human right to a healthy environment. For the above, this academic paper aims to expose the possible impacts that the constitutional change would provoke on the legal sphere of the communities located in hydrocarbon profile regions, as well as possible legal measures that could be established based on the legal parameters that this fundamental right establishes to contain this impact.

* Catedrático CONACyT adscrito al Centro de Investigaciones Sociales de la Universidad Autónoma de Tamaulipas y miembro del Sistema Nacional de Investigadores. Dirección: Edificio Centro de Gestión del Conocimiento, tercer piso, Centro Universitario Adolfo López Mateos, Ciudad Victoria, Tamaulipas. Correos: enocalejandrogarcia@gmail.com yeagarcia@uat.edu.mx.

Boletín Mexicano de Derecho Comparado, nueva serie, año XLIX, núm. 150, septiembre-diciembre de 2017, pp. 1115-1147

Esta obra está bajo una Licencia Creative Commons Atribución-NoComercial-SinDerivar 4.0 Internacional, IIJ-UNAM. 
del entorno social ubicado en las regiones de perfil hidrocarburífero, así como las posibles medidas legales que se podrían establecer para contenerlo, a partir de los parámetros jurídicos que ese derecho fundamental establece.

Palabras clave: reforma, Constitución, hidrocarburos, derechos humanos, seguridad energética.
Keywords: Reform, Constitution, hydrocarbons, human rights, energy security. 


\begin{abstract}
SUMARIO: I. Introducción. II. La reforma constitucional de los hidrocarburos. La nueva forma jurídica instaurada para su explotación. III. Las expectativas económicas regionales en torno a la explotación de los hidrocarburos. IV. Los posibles efectos jurídicos en materia ambiental dentro del contexto social de las regiones con presencia de hidrocarburos. V. Conclusiones. VI. Fuentes consultadas.
\end{abstract}

\title{
I. INTRODUCGIÓN
}

El abastecimiento de energía para cualquier país es fundamental; a través de su suministro se solventa la realización de gran parte de las actividades productivas que sostienen su economía, por lo que su carencia inexcusablemente se convierte en un grave obstáculo que impide el adecuado desarrollo nacional tanto en lo económico como en lo social.

Ésta fue una de las principales premisas por las que el gobierno federal optó realizar diversas medidas de gran relevancia en su ámbito jurídico, pues consideró inaplazable la necesidad de impulsar el aumento de la producción de energía hidrocarburífera, a fin de garantizar un suministro suficiente y de largo plazo para el país.

De acuerdo con los datos obtenidos por el gobierno federal, la productividad del país se ha visto afectada por el déficit existente entre la producción y el consumo nacional de hidrocarburos, toda vez que durante los últimos años su demanda se ha elevado en promedio al $2.1 \%$, mientras que su producción se ha disminuido en promedio al $0.3 \%$, encareciendo consecuentemente los costos de producción y de vida en México. ${ }^{1}$

Este déficit energético originado por la falta de un aumento en la producción se lo atribuyó el gobierno federal a la falta de capacidad financiera para invertir en nuevos proyectos de explotación de hidrocarburos en aguas profundas y zonas de lutitas, por lo que, para revertirla, instrumentó una planeación estatal fundamentada en el establecimiento de medidas legales dirigidas a optimizar su capacidad productiva mediante la coinversión de recursos públicos y privados.

Bajo esa intención oficial fue que inició la actualización y desarrollo del marco normativo, orientado a renovar a la industria petrolera mexicana, siendo su principal cimiento la reforma constitucional del 20 de diciembre de 2013. Esta enmienda no sólo generó una forma jurídica dis-

1 Plan Nacional de Desarrollo 2013-2018, del 20 de mayo de 2013, pp. 45 y 46. 
tinta de explotación hidrocarburífera, sino también grandes expectativas de desarrollo nacional y regional, especialmente en las zonas territoriales donde la presencia de hidrocarburos en el subsuelo se ha prospectado abundante.

En efecto, a partir de esta enmienda constitucional se están generando más y mayores proyectos de explotación para las zonas geográficas con presencia de hidrocarburos, lo que está representando, y representará, un acrecentamiento de las actividades industriales extractivas en sus territorios, y una consecuente interacción con la esfera jurídica que envuelve al entorno ambiental y social que se encuentra en ellos.

Por lo anterior, el trabajo académico que se presenta busca abordar el estudio de los distintos efectos que se darían a nivel regional como consecuencia de la dinámica económica provocada por la reforma constitucional, pues, independientemente del auge y mejoramiento que podría ocasionar, también existe la posibilidad de que origine otro tipo de efectos de contenido diverso al prospectado.

De manera particular, el análisis se enfocará al posible impacto que tendrían las actividades de explotación de hidrocarburos en el goce y ejercicio del derecho humano a un medio ambiente sano de los pobladores situados en las regiones de perfil hidrocarburífero, así como a los parámetros legales que el derecho fundamental en referencia instaura, para que a partir de éstos se busquen plantear vías jurídicas que permitan aminorar el posible efecto pernicioso sobre su esfera jurídica de protección.

Asimismo, y para mejor contextualizar, se empleará de ejemplo al estado de Tamaulipas, ya que además de ser considerado como uno de los estados con mayor proyección de explotación de hidrocarburos por la alta presencia de este recurso natural en su subsuelo y costas, es uno de los estados con una marcada presencia de población rural debido a que sus actividades económicas predominantes son las de tipo agropecuario, lo que genera, sin duda, una mayor dependencia social y económica hacia las condiciones ambientales.

Efectivamente, por las características geológicas y socioeconómicas que Tamaulipas tiene, es posible apreciar de mejor forma la acción que se dará entre la actividad industrial de explotación de hidrocarburos y el entorno ambiental con presencia social, así como los efectos que la primera produce sobre los segundos, lo que brinda una apropiada condición para

Esta obra está bajo una Licencia Creative Commons

Atribución-NoComercial-SinDerivar 4.0 Internacional, IIJ-UNAM.

Boletín Mexicano de Derecho Comparado, núm. 150, pp. 1115-1147 
observar las posibles alteraciones que acaecerían sobre la esfera jurídica establecida por el derecho humano al medio ambiente sano.

\section{LA REFORMA GONSTITUGIONAL DE LOS HIDROCARBUROS. LA NUEVA FORMA JURÍDICA INSTAURADA PARA SU EXPLOTACIÓN}

El gobierno de México en 2013 estableció dentro de su proyección de desarrollo nacional, la democratización de la productividad ${ }^{2}$ en el área energética, como una de las principales directivas para alcanzar el desarrollo económico y social del país y sus regiones, ya que con base en la planeación dirigida al aprovechamiento de los hidrocarburos nacionales se consideró que podría obtenerse una seguridad energética ${ }^{3}$ capaz de solventar un crecimiento económico y una equidad social a largo plazo.

Así, dicho planteamiento figuró como una de las políticas públicas más destacadas para encauzar las estrategias dirigidas a generar el entorno más adecuado para brindar las mejores condiciones de vida entre la población, pues mediante su implementación se buscaría impactar favorablemente al sector productivo del país, a fin de generar un mayor número de empleos y un crecimiento económico estable.

Por tanto, el cometido principal de la estrategia política de democratización de la energía radicó en incentivar las acciones necesarias para remover los obstáculos normativos y administrativos que desfavorecieran la productividad del sector energético, y, por consecuencia, de los sectores económicos y sociales del país.

De manera específica, el gobierno federal elaboró un programa sectorial de energía que contenía los objetivos particulares que se pretendían para el sector de los hidrocarburos, ${ }^{4}$ que no eran otros más que los de

2 El Plan Nacional de Desarrollo 2013-2018 define a este concepto, y dice que "significa, en resumen, que las oportunidades y el desarrollo lleguen a todas las regiones, a todos los sectores y a todos los grupos de la población”, 20 de mayo de 2013, p. 9.

3 Paul Roberts señala que en el nivel más elemental, la seguridad energética se refiere a la capacidad para satisfacer una demanda de energía de manera inmediata, esto es, a "producir volúmenes adecuados de combustible y electricidad a precios asequibles y llevar esa energía a los países que la necesitan en cada momento y poder así mantener sus economías en funcionamiento, alimentar sus habitantes y defender sus fronteras nacionales". El fin del petróleo, Barcelona, Ediciones B, 2010, p. 343.

4 Para ampliar, $c f$ r. el Programa Sectorial de Energía 2013-2018, del 13 de diciembre de 2013, pp. 16-19. 
permear en el contexto normativo, disposiciones encaminadas a configurar una mayor capacidad para realizar las actividades de exploración y extracción del recurso natural por parte del Estado mexicano.

Básicamente lo que el programa sectorial planteó fue establecer un sistema de normas y reglas que facilitaran la inversión privada tanto en los proyectos vigentes como en los futuros del sector industrial de los hidrocarburos; es decir, la instrumentación que el programa sectorial propuso, y sobre el cual se gestaron los futuros cambios normativos, estribó esencialmente en potenciar la participación de la inversión privada en la explotación de los hidrocarburos nacionales, a fin de que se aumentara su producción - garantización energética - y por ello se redujera su costo - productividad democratizada-.

Establecidas las directivas políticas y administrativas sectoriales, lo siguiente fue, acorde a la planeación oficial, impulsar las modificaciones jurídicas detalladas y específicas para suprimir los impedimentos legales que de acuerdo con el gobierno nacional afectaban, en lo general, el desarrollo de la industria petrolera mexicana y, en lo particular, el desarrollo de más y mayores proyectos de exploración, extracción y explotación de hidrocarburos.

La actualización del marco normativo encargado de renovar la industria de los hidrocarburos mexicanos fue entonces el siguiente paso en el proceso de renovación de la industria hidrocarburífera mexicana. Como consecuencia, el 12 de agosto de 2013 se presentó la iniciativa de decreto mediante el cual se propuso reformar los artículos 27 y 28 de la Constitución federal del 5 de febrero de 1917.

La iniciativa de reforma constitucional sustancialmente se formuló en el ánimo de los objetivos planteados por el programa sectorial, ya que su exposición de motivos se soportó en el razonamiento de garantizar la seguridad energética sobre la cual se promovería el desarrollo económico y social de la nación, bajo el uso de técnicas de recuperación mejorada; las cuales, por sus características financieras, hacían necesario el cambio constitucional dirigido a permitir la participación de la inversión privada en las actividades que el Estado ejercía de manera monopólica, sobre el área de los hidrocarburos. ${ }^{5}$

5 Apunta Jaime Cárdenas Gracia, que uno de los objetivos que el documento reformatorio señalaba era el que México aprovechara y fuera parte de la revolución energética 
Con motivo de lo anterior, la primera modificación legal que se propuso a través de la iniciativa de reforma del 13 de agosto de 2013 fue la relacionada con eliminar la prohibición constitucional que el artículo 27 de la carta magna le establecía al Estado mexicano para celebrar contratos de explotación de hidrocarburos con particulares.

Mientras que el segundo cambio que se enunció para la Constitución fue el encaminado a redactar en el artículo 28, que las actividades relacionadas con la exploración y extracción de hidrocarburos se podrían realizar en los términos dispuestos del artículo 27 constitucional; es decir, aun cuando fueran dichas actividades monopólicas estatales, éstas podrían ser realizadas por entes públicos y privados, previo contrato que para tal efecto se celebrara con el Estado mexicano. ${ }^{6}$ Realizado el proceso legislativo, la iniciativa de decreto de reforma se aprobó en los términos generales propuestos mediante la iniciativa, dado que la redacción constitucional se cambió en el sentido de permitirle al Ejecutivo Federal la suscripción de contratos a través de los cuales se estipularía la explotación y extracción de los hidrocarburos nacionales en asociación con otros entes distintos al Estado mexicano. ${ }^{7}$

A la postre, y como consecuencia jurídica de esta nueva redacción constitucional, el 11 de agosto de 2014 se publicó en el Diario Oficial de la Federación, la Ley de Hidrocarburos, ordenamiento jurídico que de manera directa operativiza la desmonopolización pública que recayó sobre la explotación de los hidrocarburos nacionales. De manera específica, la Ley de Hidrocarburos, del 11 de agosto de 2014, establece la permisión constitucional para explotar hidrocarburos mexicanos por parte del sector privado en su artículo 23, precepto que a la letra señala:

de América del Norte: "para convertir a la energía en un factor de competitividad en todos los sectores de la economía, pues mantener una postura pasiva implica incrementar nuestra dependencia energética del exterior; la creación de mercados eficientes de hidrocarburos es una condición necesaria para incrementar la competitividad del país". Crítica a la reforma constitucional energética 2013, México, UNAM, Instituto de Investigaciones Jurídicas, 2014, p. 22.

6 Iniciativa de Decreto por el que se reforman los artículos 27 y 28 de la Constitución de los Estados Unidos Mexicanos, del 12 de agosto de 2013, pp. 9, 10 y 13.

7 García Rivera, Enoc Alejandro, "La renovada regulación constitucional de los hidrocarburos nacionales", Revista Mexicana de Derecho Constitucional, núm. 33, julio-diciembre de 2015, pp. 62-75. 
Artículo 23. La adjudicación de los Contratos para la Exploración y Extracción se llevará a cabo mediante licitación que realice la Comisión Nacional de Hidrocarburos. Las bases de licitación preverán que el Contrato para la Exploración y Extracción se podrá formalizar con Petróleos Mexicanos, otras empresas productivas del Estado y Personas Morales, ya sea de manera individual, en consorcio, o asociación en participación...

Con este nuevo esquema constitucional y normativo se anuló a partir del 20 de diciembre de 2013, la estructura jurídica que por décadas había imperado como la forma legal de explotación del petróleo y gas del Estado mexicano, dando paso a la reanudación de la forma de explotación de hidrocarburos nacionales previa a la expropiación de la industria hidrocarburífera nacional, ${ }^{8}$ aquella que permitía la participación de la inversión privada.

\section{LAS EXPEGTATIVAS ECONÓMICAS REGIONALES EN TORNO A LA EXPLOTACIÓN DE LOS HIDROCARBUROS}

Los beneficios que se han pronosticado a nivel nacional con la reforma constitucional energética han sido optimistas para las áreas social y económica, ya que con el aumento de la producción y extracción de hidrocarburos nacionales que se ha estimado se espera, entre otras cosas favorables pronosticadas, abastecer la demanda de energía doméstica e industrial del país sin necesidad de importarla, lo que evitaría asumir el costo adicional implicado y la dependencia energética exterior.

Estas expectativas de garantización del abasto energético se sustentan en datos que auguran un aumento en la explotación del petróleo y gas natural a partir del incremento de las actividades de exploración y extracción. En el caso del petróleo, la producción que se espera obtener en los

8 Para profundizar sobre la forma de explotación previa a la expropiación de la industria petrolera de 1938, cfr. a Rivera Castro, José, "La expropiación petrolera. Raíces históricas y respuesta de los empresarios extranjeros", Revista Casa del Tiempo, época IV, vol. I, núm. 8, junio de 2008, pp. 1-7; Clave Almeida, Eduardo, "La riqueza del archivo histórico de Petróleos Mexicanos", América Latina en la Historia Económica. Revista de Fuentes e Investigación, vol. 23, enero-junio de 2005, pp. 131-137 y Anaya Merchant, Luis (coord.), Historia económica regional, Ciudad Victoria, Universidad Autónoma de Tamaulipas, vol. IV, 2013, colección Lecturas Históricas de Tamaulipas, pp. 413-437.

Esta obra está bajo una Licencia Creative Commons

Atribución-NoComercial-SinDerivar 4.0 Internacional, IIJ-UNAM.

Boletín Mexicano de Derecho Comparado, núm. 150, pp. 1115-1147 
próximos diez años es de 2.5 millones de barriles diarios a 3.5 millones, mientras que en la de gas natural es de 5 mil 700 millones de pies cúbicos diarios a 10 mil 400 millones. $^{9}$

Resulta importante resaltar que para cualquier Estado el sector energético de los hidrocarburos va más allá de representarle la provisión de un medio de energía que supla las necesidades domésticas de sus sectores económico y social, pues, como apunta Ortuño Zarate, el sector energético constituye un elemento sustancial y consolidador de la soberanía y la integración de un país como nación. ${ }^{10}$

Para México, sin ser la excepción, el sector energético ha sido un factor fundamental para su consolidación e integración como Estado, ya que a lo largo de la historia contemporánea el sector energético de los hidrocarburos ha impactado de manera por demás definitiva y favorable en su proceso económico y de industrialización.

$\mathrm{Al}$ respecto, Aguilera Gómez señala que la industria de los hidrocarburos siempre ha impulsado a la demás industria mexicana, puesto que desde sus inicios con la extracción de crudo, la modernización de las refinerías y la multiplicación de los ductos por todo el territorio nacional dio un primer impulso a la industria nacional, particularmente a la industria siderúrgica; para posteriormente, con la incursión en la petroquímica, de nuevo inyectar dinamismo al proceso económico del país. ${ }^{11}$

Es posible apreciar que con el cambio constitucional se busca posicionar de nueva cuenta al sector energético de los hidrocarburos, como el área de impulso de la económica mexicana, tanto por medio de la garantización del abasto de energía como por la gran cuota de aportación directa e indirecta que hace a la actividad económica del país, y por supuesto a sus regiones.

9 Iniciativa de Decreto por el que se reforman los artículos 27 y 28 de la Constitución de los Estados Unidos Mexicanos, del 12 de agosto de 2013, p. 15.

10 Ortuño Zarate, Salvador, El mundo del petróleo, México, Fondo de Cultura Económica, 2009, p. 153.

11 Manuel Aguilera Gómez concluye que "Un país puede desarrollarse sin metales preciosos, sin minerales industriales, pero no puede sobrevivir sin hidrocarburos. La vida moderna es inconcebible sin la energía proveniente de los hidrocarburos, y sin esa materia prima esencial para la fabricación de múltiples productos". El petróleo mexicano. Conflicto, esperanza y frustración, México, M. A. Porrúa-UNAM, 2015, pp. 64 y 142.

Esta obra está bajo una Licencia Creative Commons Atribución-NoComercial-SinDerivar 4.0 Internacional, IIJ-UNAM. Boletín Mexicano de Derecho Comparado, núm. 150, pp. 1115-1147 
Sobre esto, Alpizar Vallejo menciona que la reforma energética implica para el país, por un lado, a nivel nacional, un elemento fundamental para replantear las posibilidades de desarrollo para la presente generación y la próxima, y por el otro, a nivel regional, la necesidad de políticas públicas en materia industrial que deriven en un fomento a la generación de empleos, al avance tecnológico y a la inclusión social; es decir, a una desconcentración de la riqueza, con el fin de balancear las disparidades y la heterogeneidad características de la economía mexicana. ${ }^{12}$

Complementa lo anterior Barcon Palomar, al señalar que la industrialización desde siempre y a nivel mundial ha tenido una relación inexorable con la energía, siempre ligada una de otra, la que algunos países han aprovechado plenamente para, con la generación de energía, potenciar el resto de sus cadenas productivas. ${ }^{13}$

En esa tónica, la proyección nacional de desarrollo económico y social que se ha conformado a partir del aumento de la explotación de hidrocarburos se ha visto replicada en su proporción a nivel regional, toda vez que los gobiernos estatales han realizado su propia planificación de desarrollo para sus gobiernos, territorios y población, con el objetivo de no aislarse del impulso económico que se pretende dar mediante la jurídicamente revitalizada industria de los hidrocarburos.

Sirve de ejemplo el estado de Tamaulipas, entidad federativa en cuyo subsuelo y costas existe una profusa presencia del recurso natural energético, lo que lo sitúa como uno de los estados con mayor prospección para recibir un auge económico considerable por el aumento de las actividades industriales vinculadas a la explotación de los hidrocarburos.

En efecto, en esta entidad federativa se está esperando como resultado de la reforma constitucional de los hidrocarburos, una derrama económica que impactará en sus ámbitos privado, social y gubernamental, ya que dentro de su territorio se ubican tres de los yacimientos más importantes del país, dos terrestres: el Activo Integral Burgos y el Activo de Producción Poza

12 Alpizar Vallejo, Rodrigo, "El consorcio o la asociación industrial como una estrategia de oportunidad de la industria nacional dentro de la reforma energética del país", en Oropeza García, Arturo (coord.), Reforma energética y desarrollo industrial. Un compromiso inaplazable, México, UNAM, Instituto de Investigaciones Jurídicas, 2015, p. 224.

13 Barcon Palomar, Santiago, “¿Energía o anarquía en materia energética? Cómo aprovechar la reforma energética en materia industrial”, en Oropeza García, Arturo (coord.), op. cit., p. 344.

Esta obra está bajo una Licencia Creative Commons

Atribución-NoComercial-SinDerivar 4.0 Internacional, IIJ-UNAM.

Boletín Mexicano de Derecho Comparado, núm. 150, pp. 1115-1147 
Rica-Altamira, y uno marítimo: el Proyecto Cinturón Plegado Perdido, todos ricos en gas, gasolina, petróleo y aceite terciario. ${ }^{14}$

Estas condiciones geológicas y jurídicas son las que han generado en esa entidad federativa altas expectativas de desarrollo económico y social, y por las que ya se ha contemplado una planificación pública ${ }^{15}$ orientada a potencializar las actividades económicas locales que de alguna manera estarán vinculadas con la intensa explotación de hidrocarburos que se ha planeado desarrollar en los próximos años. ${ }^{16}$

Es perceptible lo anterior al examinar la planeación regional que, desde un enfoque predominantemente económico, el ámbito de gobierno estatal ha elaborado, pues ya ha plasmado todo un grupo de acciones públicas dirigidas a favorecer el desarrollo de las actividades de exploración y extracción.

En infraestructura, por ejemplo, Tamaulipas ha planeado desarrollarla en las áreas de transporte, suministro y servicios públicos, realizando para ello la ampliación y modernización de sus redes carreteras y ferroviarias, puertos marítimos y aeropuertos, así como la construcción de acueductos, presas y plantas de bombeo que ayuden a suministrar de agua a la industria de hidrocarburos, mejorando a su vez la red de agua potable, drenaje, electrificación y equipamiento urbano de los municipios donde se llegue a asentar la industria de los hidrocarburos. ${ }^{17}$

14 De acuerdo con los datos nacionales prospectados de recursos hidrocarburíferos, hasta marzo de 2014, Tamaulipas figuraba como una de las entidades con mayor riqueza de petróleo y gas natural. De hecho, de los 52.6 miles de millones de barriles de petróleo crudo convencional prospectados hasta marzo de 2014, el 63.3\% se encuentra ubicado en las provincias petroleras de Burgos, Tampico-Misantla y golfo de México profundo. Datos obtenidos de la Agenda Energética del Estado de Tamaulipas, del 10 de septiembre de 2014, pp. 10,11 y 17 .

15 En septiembre de 2014, el gobierno de Tamaulipas presentó su Agenda energética, documento a través del cual ha proyectado las acciones públicas que realizará con la finalidad de involucrarse a la dinámica económica, que las distintas actividades de explotación de hidrocarburos originarán con su arribo a tierras tamaulipecas, resultado de los cambios constitucionales en la materia de 2013.

16 De acuerdo con la Secretaría de Energía, para la cuenca de Burgos se ha estimado licitar 124 áreas de explotación, comprendidas en una superficie total de 14,406 km² situados, en su mayoría, en el estado de Tamaulipas; mientras que para el cinturón plegado de aguas profundas, ubicado en su mayor parte frente a las costas de Tamaulipas, la proyección es de $83,945 \mathrm{~km}^{2}$. Véase Plan quinquenal de licitaciones para la exploración y extracción de hidrocarburos 2015-2019, del 20 de junio de 2015, pp. 41 y 47.

17 Agenda energética Tamaulipas, pp. 57-60, 67 y 69.

Esta obra está bajo una Licencia Creative Commons Atribución-NoComercial-SinDerivar 4.0 Internacional, IIJ-UNAM. Boletín Mexicano de Derecho Comparado, núm. 150, pp. 1115-1147 
Por su parte, en el área de comercio, el estado de Tamaulipas ha planeado desplegar parques especializados en el sector hidrocarburífero para involucrar de alguna forma a las empresas locales en el flujo de negocios que se estima llegará con el auge de las actividades productivas vinculadas con la explotación del gas y del petróleo.

Es evidente que las acciones programadas a nivel nacional, y de manera particular a nivel de región hidrocarburífera, han sido las más convenientes para concurrir con la dinámica económica que el gobierno federal desea promover mediante la obtención de la seguridad energética nacional. Sin embargo, es manifiesto que la magnitud y fuerza que se le quiere transmitir a dicha dinámica no es del todo conveniente para el sector social que compagina geográficamente con la industria de los hidrocarburos.

Sin duda, junto al impacto positivo que posiblemente se originaría en las regiones, resultado del auge económico derivado del desarrollo de infraestructura y negocios complementarios a las actividades dirigidas a mejorar la seguridad energética del país, también se puede esperar otro impacto, uno que perturbaría de manera negativa a aspectos íntimamente ligados con el bienestar individual y colectivo de los pobladores situados en las regiones de perfil hidrocarburífero. ${ }^{18}$

Como precisa Roberts, la energía hidrocarburífera se ha situado como el cimiento de la riqueza, del confort y del progreso de la vida moderna; como un factor determinante en la jerarquía de las naciones por la relevancia política y económica que adquiere; como un principio geopolítico rector para todos los gobiernos; en concreto - resume - la energía hidrocarburífera se ha convertido en el recurso estratégico del cual depende el ascenso y la caída de economías y las civilizaciones, ya sea porque acaba con ellas o porque las impulsa al siguiente nivel de desarrollo tecnológico y económico.

No obstante, como continúa señalando Roberts Paul, desde la mirada más superficial que se le pueda dar a este elemento tan importante para la sociedad global, se puede descubrir que la economía energética tiene

18 Como lo hace ver Cárdenas Gracia al señalar que los objetivos económicos se destinan a lograr la máxima explotación para optimizar el mayor beneficio "sin advertir, entre otras, las consecuencias medioambientales y de salud", aspectos que se encuentran estrechamente ligados al más amplio bienestar humano, el personal y el social, op. cit., p. 23.

Esta obra está bajo una Licencia Creative Commons

Atribución-NoComercial-SinDerivar 4.0 Internacional, IIJ-UNAM.

Boletín Mexicano de Derecho Comparado, núm. 150, pp. 1115-1147 
fallos que la condenan a fracasar en casi todos los aspectos, ya que es evidente para casi todos, que la dependencia creciente de los combustibles fósiles está ligada invariablemente con cambios sutiles pero importantes en nuestro clima y, por tanto, en el entorno ambiental global. ${ }^{19}$

\section{LOS POSIBLES EFECTOS JURÍDICOS EN MATERIA AMBIENTAL DENTRO DEL CONTEXTO SOCIAL DE LAS REGIONES CON PRESENCIA DE HIDROGARBUROS}

A la par del posible desarrollo social que se llegara a generar por el auge económico originado por la explotación de estos recursos naturales, está también el posible retroceso social que esa misma explotación podría producir, ya que al aumentar la cantidad e intensidad de las actividades de la industria, las condiciones inherentes a éstas, junto con las que se han planeado para complementarlas, potencializan la generación de condiciones que pueden afectar el bienestar social.

Efectivamente, ese bienestar social que la norma constitucional promueve y protege a través de un sistema constitucional de derechos humanos se muestra vulnerable ante la posibilidad de que la esfera jurídica que los tutela sea afectada por el aumento de las actividades propias y complementarias de la renovada industria de los hidrocarburos nacionales.

Debe recordarse que el bienestar social, tras una larga evolución sociojurídica, se desenvuelve dentro del valor de la dignidad humana, el cual se solventa mediante la conjunción de otros valores, conceptos y bienes jurídicos que el derecho se ha encargado de instrumentar por medio de los derechos fundamentales redactados en los textos constitucionales. ${ }^{20}$

En el sistema estadual actual, el bien común o social se encuentra moldeado bajo los parámetros de los valores imbuidos en un sistema jurídico que positiviza los derechos esenciales de la persona, cuyo propósito ha sido el de alcanzar para el ser humano el valor universal de la dignidad

19 Roberts, Paul, op. cit., pp. 19, 20 y 45.

20 Para profundizar cfr. Castán Tobeñas, José, Los derechos del hombre, Madrid, Ralos, 1985, pp. 13 y 14; y Muñoz, Virgilio y Acuña Borbolla, Manuel, Nuestra Constitución. Historia y valores de una nación, México, Fondo de Cultura Económica, 2001, p. 46. 
individual y social, a fin de que éste logre su libre desarrollo de la personalidad en igualdad, libertad y solidaridad..$^{21}$

Lo anterior a su vez ha generado una tendencia interpretativa del alcance mínimo que cada derecho fundamental constitucionalmente positivizado debe guardar para ser efectivo en su ejercicio, ${ }^{22}$ pues ello proporciona una certeza del contenido esencial que engloba su núcleo de garantías y libertades, y sobre el cual el sistema estadual deberá operar en favor de su colectividad, con el objetivo de brindarles un estatus conveniente de dignidad a su vida. ${ }^{23}$

Partiendo de lo anterior, se procede a analizar la posible interacción que se presentará entre las actividades propias y complementarias de la industria de los hidrocarburos, y el contenido esencial de uno de los derechos humanos que posiblemente se vea afectado por el aumento intensivo de la nueva industria hidrocarburífera en las regiones donde su presencia se ha proyectado abundante: el derecho humano al medio ambiente sano.

Para las entidades federativas de perfil hidrocarburífero indudablemente se aproxima un incremento en la presión ambiental de las regiones, donde se incorporarán de manera intensiva las actividades de explotación de hidrocarburos y actividades conexas a éstas, ya que, como pre-

21 Humberto Nogueira Alcalá refiere que "La dignidad de la persona humana es el valor básico que fundamenta los derechos humanos, ya que su afirmación no sólo constituye una garantía de tipo negativo que protege a las personas contra vejámenes y ofensas de todo tipo, sino que también debe afirmar positivamente a través de los derechos el pleno desarrollo de cada ser humano y de todos los seres humanos", y agrega "La dignidad de la persona constituye el fundamento de la libertad, la igualdad y de los derechos". Teoría y dogmática de los derechos fundamentales, México, UNAM, Instituto de Investigaciones Jurídicas, 2003, pp. 145 y 146. De igual forma, para profundizar sobre el concepto de dignidad, véase Fernández Segado, Francisco, "La teoría jurídica de los derechos fundamentales en el Tribunal Constitucional", Revista Española de Derecho Constitucional, Madrid, año XIII, núm. 39, septiembre-diciembre de 1993, p. 272.

22 Gregorio Peces-Barba aborda la eficacia de la positivización de los derechos humanos en el sentido de señalar que extender "la positivización a las dimensiones de eficacia, implica analizar la realidad con lo que supone de obstáculos o impedimentos para la implementación real de las pretensiones morales convertidas en derecho de los derechos humanos. La justicia y la validez necesitan la eficacia". Derechos fundamentales, 4a. ed., Madrid, Universidad Complutense de Madrid, 1983, p. 63.

23 Véanse García Herrera, Miguel Ángel, "Principios generales de la tutela de los derechos y libertades en la Constitución española", Revista de la Facultad de Derecho de la Universidad Complutense, 1979, pp. 11 y 113; y Lorenzo Rodríguez-Armas, Magdalena, Análisis del contenido esencial de los derechos fundamentales, Granada, Comares, 1966, p. 242.

Esta obra está bajo una Licencia Creative Commons

Atribución-NoComercial-SinDerivar 4.0 Internacional, IIJ-UNAM.

Boletín Mexicano de Derecho Comparado, núm. 150, pp. 1115-1147 
cisa Pons-Jiménez, el petróleo contiene contaminantes orgánicos, como alcanos, cicloalcanos y aromáticos; compuestos polares como azufrados y orgánosulforados constituidos con nitrógeno, asfáltenos; y elementos metálicos como el vanadio y el níquel, ${ }^{24}$ lo cuales en su conjunto provocan diversos efectos negativos en el aire, agua y tierra; es decir, en todo el medio ambiente.

Así, cuando se manipulan los hidrocarburos por extracción, traslado o industrialización, los elementos que contienen se propagan originando los siguientes efectos contaminantes: en el agua, una disminución del contenido de oxígeno y salinidad; en el aire, una captación de dióxido de carbono, monóxido de carbono y ácido sulfhídrico, lo que contamina extensas zonas en la dirección de los vientos; en la flora, una presencia en el tejido de los arbustos, matorrales y pastizales, que normalmente se emplean como alimento del ganado destinado al consumo humano, y en las costas, daños irreversibles en la fauna marina. ${ }^{25}$

Salvador Ortuño Zárate corrobora lo anterior al señalar que la explotación intensiva de yacimientos da como resultado problemas de contaminación y deterioro ambiental por los métodos de explotación y refinación empleados, así como por los derrames de hidrocarburos en regiones continentales y mares en atención a su transporte y manejo, y se podría agregar por el desarrollo de infraestructura complementaria a cada una de las actividades de valor de la industria hidrocarburífera. ${ }^{26}$

24 Pons-Jiménez, Mirna et al., "Extracción de hidrocarburos y compuestos derivados del petróleo en suelos con características físicas y químicas diferentes", Revista Universidady Ciencia, vol. XXVII, núm.1, abril de 2011, p. 2.

25 Para apreciar a detalle $c f r$. Guía de recomendaciones para proteger el medio ambiente durante el desarrollo de la exploración y explotación de hidrocarburos, Buenos Aires, Instituto Argentino del Petróleo, 1991.

26 Ortuño Zárate precisa: "En este aspecto se consideran los daños en los ecosistemas debido a las actividades de la cadena de valor o de procesos del petróleo y sus derivados, desde la exploración (v. gr., la utilización de explosivos para el levantamiento de datos sísmicos), la explotación de yacimientos, la producción (los derrames de hidrocarburos en zonas petroleras dañan el suelo y la hidrosfera, o la quema de gas asociado), la refinación (los productos de desecho)... La contaminación marina provocada, generalmente, por los derrames de hidrocarburos en los ecosistemas marinos, debido a los accidentes en oleoductos y gasoductos, o en maniobras de rutina de los barcos petroleros y metaneros". Op. cit., p. 165. 
En México, señala Ortínez Brito, la industria del petróleo en su conjunto ha tenido un impacto negativo en materia ambiental, por la grave contaminación que provoca en suelos y en cuerpos de agua, lo que se agrava aún más con el alto grado de dificultad y de costo que conlleva su remediación, esto en caso de ser viable. ${ }^{27}$

De manera particular, las regiones de perfil hidrocarburífero son las primeras en estar propensas al impacto negativo que la industria de los hidrocarburos puede provocar en su entorno ambiental, y, por consecuencia, en la esfera jurídica de protección constitucional que recae sobre la misma en relación con los habitantes que deben gozar de su adecuado goce y ejercicio.

En el caso de la entidad federativa que se propuso de ejemplo, se observa que a partir de la reforma constitucional se le ha proyectado un aumento considerable en las actividades de explotación en su zona noreste, lo que muy probablemente desembocaría en una confrontación con aspectos jurídicos de relevancia social, como lo es el derecho humano a un medio ambiente sano

Y es que la zona noreste de Tamaulipas, además de ser muy rica en hidrocarburos, específicamente en gas, es una región donde se tiene una alta presencia de población rural $^{28}$ por la vasta actividad agrícola de cultivo de sorgo que se realiza, ${ }^{29}$ la cual, de igual manera, depende directamente de las óptimas condiciones ambientales.

Esta situación hace aún más propensa la posibilidad de evidenciar la afectación al goce y ejercicio del derecho a un medio ambiente sano, ya que los contaminantes que propaga la actividad industrial de los hidrocarburos no sólo afectarían el aire que respiran los pobladores ubicados en dicha zona, sino también a las tierras, el agua, la flora y la fauna que emplean como su medio de subsistencia.

27 Ortínez Brito, Óscar et al., "La restauración de suelos contaminados con hidrocarburos en México", Gaceta Ecológica, núm. 69, octubre-diciembre de 2003, pp. 83-92.

28 En la zona norte de Tamaulipas se ubican 335 ejidos habitados por 33,608 personas, una propiedad de 522,591 hectáreas. Datos obtenidos del Padrón e Historial de Núcleos Agrarios (PHINA) del Registro Agrario Nacional, enero de 2016.

29 En la primera época de siembra de 2016, en Tamaulipas se sembraron 650,357 hectáreas de sorgo en grano y 162,157 de maíz en grano, cantidades que permitieron situar a Tamaulipas como el primer productor de sorgo y el tercer productor de maíz en todo el país. Datos obtenidos del Servicio de Información Agroalimentaria y Pesquera de la Secretaría de Agricultura, Ganadería, Desarrollo Rural, Pesca y Alimentación.

Esta obra está bajo una Licencia Creative Commons

Atribución-NoComercial-SinDerivar 4.0 Internacional, IIJ-UNAM.

Boletín Mexicano de Derecho Comparado, núm. 150, pp. 1115-1147 
En efecto, esa actividad industrial provoca un fuerte deterioro en los ecosistemas por las aguas congénitas que produce, la deforestación que origina por el cambio de uso de suelo y los residuos contaminantes que esparce, lo que afectaría a la salud de la población, y no sólo a ésta, sino al cereal que se produce en la zona, que además de ser empleado como su medio económico de subsistencia es en su mayoría destinado para la engorda de animales de consumo humano a nivel regional y nacional. ${ }^{30}$

Cabe resaltar también, que esta interacción y posibles afectaciones de la industria extractiva de los hidrocarburos en relación con el derecho humano a un medio ambiente han sido previstas incluso dentro de los marcos normativos federales encargados de regular la nueva forma constitucional de explotación: la Ley de Hidrocarburos y la Ley de Ingresos de Hidrocarburos, del 11 de agosto de 2014.

La Ley de Hidrocarburos, en sus artículos 101, fracción VI, inciso a y 104, fracción V, por ejemplo, prevé que dentro del concepto de contraprestación que se les deberá pagar a los titulares de las tierras donde se realizarán las tareas de explotación de hidrocarburos se deberá incluir el costo de los daños y perjuicios que se les ocasionará en su tierra por la realización de dichas tareas.

Por su parte, la Ley de Ingresos sobre Hidrocarburos, en su artículo 57, fracción II, prevé que el Fondo para Entidades Federativas y Municipios Productores de Hidrocarburos, que se integrará con los recursos recaudados por el impuesto por la actividad de exploración y extracción de hidrocarburos, deberá ser destinado por lo menos en un $20 \%$ de su monto a los municipios que registren daño al entorno social y ecológico derivado de la actividad de exploración y extracción de hidrocarburos. ${ }^{31}$

30 Para ampliar sobre los impactos sociales de la explotación de hidrocarburos en el norte de Tamaulipas, $c f r$. Roux, Ruth, Impactos sociales de la extracción de gas lutitas en Tamaulipas, México, Plaza y Valdez-UAT, 2016, pp. 129-157; y Morales Ramírez, Dionicio, "Evaluación del impacto social en las actividades de extracción del gas shale y el boom-bust cycle", en Roux, Ruth (coord.), Los hidrocarburos en el noreste de México. Una mirada multidisciplinaria, Victoria, Colegio Tamaulipas-UAT, 2016, pp. 138-153.

31 Para ampliar sobre este fondo $c f r$. García Rivera, Enoc Alejandro, "La nueva enmienda constitucional de los hidrocarburos y su vinculación con las finanzas municipales", en Anglés Hernández, Marisol (coord.), Reforma en materia de hidrocarburos. Análisis jurídicos, sociales y ambientales en prospectiva, México, UNAM-UAT, 2017, pp. 67-70, así como el Acuerdo $07 / 2015$, por el que se emiten las reglas de operación para la distribución y aplicación 
Esta regulación legal, sin duda, lleva a considerar la irrefutable posibilidad de que la renovada industria de los hidrocarburos impacte negativamente en el entorno ambiental de las zonas proyectadas para explotación, y, por consecuencia, en el entorno social vinculado directamente a éste.

Asimismo, lleva a considerar que el planteamiento jurídico que el Estado mexicano realiza entre la renovada industria de los hidrocarburos que propuso para garantizar el abastecimiento de energía y el medio ambiente se encuentra distanciado de los principios que solventan el derecho humano a un medio ambiente sano, pues, lejos de buscar prevenir los daños ambientales que se puedan ocasionar, los asume como parte consustancial del costo que conlleva la obtención de la seguridad energética nacional.

Como se puede apreciar, la implementación masiva de las actividades sustanciales a la industria, y económicas adicionales a la misma, potenciaría con mayor intensidad la generación de pasivos ambientales en los ecosistemas de las regiones de perfil petrolero de Tamaulipas, lo que afectaría el adecuado goce y ejercicio del derecho fundamental a un medio ambiente sano instaurado jurídicamente a nivel internacional y doméstico, a través de los tratados internacionales y la Constitución mexicana.

Debe recordarse que el derecho humano a un medio ambiente sano ha transitado una evolución jurídica de poco más de cuatro décadas, resultado de la necesidad de establecer medidas que ayudaran a congeniar los crecientes requerimientos humanos con los limitados recursos del planeta, ya que el aumento exponencial en la demanda de producción de alimentos y de energía, así como de otros recursos no renovables como el agua, empezaron a afectar gravemente el entorno ambiental y, por consiguiente, la calidad de vida de los seres humanos. ${ }^{32}$

Efectivamente, como señala Álvarez Molina, este derecho fundamental nació de la enorme relevancia social que presentó a nivel mundial el garantizar la tutela jurídica efectiva de la salud y el equilibrio ecológico,

de los recursos del Fondo para Entidades Federativas y Municipios Productores de Hidrocarburos, del 4 de junio de 2015, emitido por la Secretaría de Hacienda y Crédito Público.

32 Benglio Valdéz, Mariana, "Derecho humano a un medio ambiente sano", Sexto certamen de ensayo sobre derechos humanos. El derecho humano a un medio ambiente sano, México, Comisión de Derechos Humanos del Estado de México, 2003, p. 188.

Esta obra está bajo una Licencia Creative Commons

Atribución-NoComercial-SinDerivar 4.0 Internacional, IIJ-UNAM.

Boletín Mexicano de Derecho Comparado, núm. 150, pp. 1115-1147 
ya que se reconoció como uno de los aspectos imprescindibles para brindarle al ser humano una vida digna en el planeta. ${ }^{33}$

Un primer indicio jurídico internacional vinculado con el derecho humano al medio ambiente sano lo constituye el artículo 95, inciso $c$, numeral 1, de la Carta Constitutiva de la Organización de Estados Americanos, del 30 de abril de 1948, precepto que establecía la obligación del Consejo Interamericano para el Desarrollo Integral, de ejecutar programas y proyectos de desarrollo económico social que contemplaran temas relacionados con el medio ambiente. ${ }^{34}$ Sin embargo, su limitado alcance y relevancia jurídica sólo le permite ser ubicado como un pequeño vestigio normativo internacional en materia de medio ambiente. ${ }^{35}$

En cambio, la Declaración de Estocolmo sobre el Medio Ambiente Humano, del 16 de junio de 1972, es considerada el instrumento jurídico más importante para el derecho humano a un medio ambiente sano, no sólo por haber sido quien lo gestó como un derecho fundamental para el

33 Álvarez Molina, Marianella, "Los alcances del derecho a un ambiente sano y ecológicamente equilibrado en Costa Rica", Foro Constitucional Iberoamericano, año III, núm. 9, enero-abril de 2005, p. 38.

34 Artículo 95, inciso $c$, numeral 1 de la Carta Constitutiva de la Organización de Estados Americanos, del 30 de abril de 1948, que a letra señala:

"Artículo 95. (...) para alcanzar diversos fines, particularmente en el área específica de la cooperación técnica, el Consejo Interamericano para el Desarrollo Integral deberá:

c) Promover, coordinar, responsabilizar de la ejecución de programas y proyectos de desarrollo a los órganos subsidiarios y organismos correspondientes, con base en las prioridades determinadas por los Estados miembros, en áreas tales como:

1) Desarrollo económico social, incluyendo el comercio, turismo, la integración y el medio ambiente".

Otros antecedentes de regulación internacional ambiental son: el Acuerdo para la Protección de las Aves, del 19 de marzo de 1902, los tratados para la protección de ballenas, del 24 de agosto de 1931, y sobre la prevención de la contaminación de los mares por el petróleo, del 12 de mayo de 1954, en Rojas Amandi, Víctor Manuel, "El derecho internacional público del medio ambiente al inicio del siglo XXI", Anuario Mexicano de Derecho Internacional, vol. II, enero-diciembre de 2002, p. 338.

35 Christian Vidal León señala que en ese instrumento jurídico internacional, el medio ambiente es abordado como una situación de interés exclusivo para los Estados, dejando de lado la participación de los individuos, tanto en su protección como en su defensa ante cualquier daño sufrido a consecuencia de su afectación. Vidal León, Christian, "El derecho al medio ambiente sano y su evolución internacional. Logros y retos", Sexto certamen de ensayo sobre derechos humanos. El derecho humano a un medio ambiente sano, México, Comisión de Derechos Humanos del Estado de México, 2003, p. 126.

Esta obra está bajo una Licencia Creative Commons Atribución-NoComercial-SinDerivar 4.0 Internacional, IIJ-UNAM. Boletín Mexicano de Derecho Comparado, núm. 150, pp. 1115-1147 
ser humano, ${ }^{36}$ sino por haber establecido las bases sobre las cuales se ha desarrollado jurídicamente.

La Declaración de Estocolmo, además de haber concebido al derecho al medio ambiente como un derecho humano, estableció las bases sobre los cuales se originaría su propia evolución jurídica, pues a partir de ésta se empezó a generar su desarrollo legal en otros documentos normativos de derecho internacional y nacional, y su interpretación jurídica por parte de los órganos jurisdiccionales de la misma índole. ${ }^{37}$

Y es que como parte del efecto jurídico posterior que tuvo la Declaración de Estocolmo, surgieron diversos instrumentos jurídicos internacionales que vinieron a robustecer el contenido y alcance del recién gestado derecho humano al medio ambiente sano, destacándose la Declaración de

36 El principio 1 de la Declaración de Estocolmo sobre el Medio Ambiente Humano, del 16 de junio de 1972, fue el texto encargado de establecer por primera vez el derecho al medio ambiente sano como un derecho humano:

"Principio 1. El hombre tiene derecho fundamental a la libertad, la igualdad y el disfrute de condiciones de vida adecuadas en un medio ambiente de calidad tal que le permita llevar una vida digna y gozar de bienestar, y tiene la solemne obligación de proteger y mejorar el medio ambiente para las generaciones presentes y futuras. A este respecto, las políticas que promueven o perpetúan el apartheid, la segregación racial, la discriminación, la opresión colonial y otras formas de opresión y de dominación extranjera quedan condenadas y deben eliminarse".

37 Algunos de los fundamentos que se pueden destacar de esta Declaración son: el de responsabilidad intergeneracional; el de desarrollo sustentable; el de conservación del medio ambiente, y el de planificación del desarrollo, los cuales se extraen de los siguientes principios instaurados por la Declaración de Estocolmo sobre el Medio Ambiente Humano:

"Principio 2. Los recursos naturales de la tierra incluidos el aire, el agua, la tierra, la flora y la fauna y especialmente muestras representativas de los ecosistemas naturales, deben preservarse en beneficio de las generaciones presentes y futuras, mediante una cuidadosa planificación u ordenación, según convenga.

Principio 3. Debe mantenerse y, siempre que sea posible, restaurarse o mejorarse la capacidad de la tierra para producir recursos vitales renovables.

Principio 4. El hombre tiene la responsabilidad especial de preservar y administrar juiciosamente el patrimonio de la flora y la fauna silvestres y su hábitat, que se encuentran actualmente en grave peligro por una combinación de factores adversos. En consecuencia, al planificar el desarrollo económico debe atribuirse importancia a la conservación de la naturaleza, incluidas la flora y la fauna silvestres.

Principio 5. Los recursos no renovables de la tierra deben emplearse de forma que se evite el peligro de su futuro agotamiento y se asegure que toda la humanidad comparte los beneficios de tal empleo...".

Esta obra está bajo una Licencia Creative Commons

Atribución-NoComercial-SinDerivar 4.0 Internacional, IIJ-UNAM.

Boletín Mexicano de Derecho Comparado, núm. 150, pp. 1115-1147 
Río sobre el Medio Ambiente y el Desarrollo, del 14 de junio de 1992, ${ }^{38}$ la Declaración de Johannesburgo sobre Desarrollo Sostenible, del 4 de septiembre de 2002 y, a nivel regional internacional, el Protocolo de San Salvador, del 17 de noviembre de 1988. ${ }^{39}$

Mientras que en lo concerniente a su desarrollo jurídico doméstico las Constituciones han sido las encargadas de reflejar sus efectos para fungir consecuentemente como sus principales operadoras normativas, toda vez que sus textos han sido modificados para fijar de manera general su alcance legal de garantización hacia el interior de cada país, tanto por medio de su redacción como por medio de las demás normas internas de carácter federal, regional y municipal que se ajustan a las mismas.

En el caso de México, su desarrollo normativo se presentó a través de la enmienda constitucional del 8 de febrero de 2012, la cual modificó el texto del artículo 4o. de la Constitución mexicana, para incorporarlo, lo que generó para el Estado mexicano la obligación de garantizar en favor de toda persona el ejercicio de su derecho a un medio ambiente sano para acceder a un desarrollo y bienestar individual y colectivo pleno; esto es, el velar por que toda persona subsista en un medio ambiente lo suficientemente saludable para propiciarle su completo desarrollo en lo individual y en lo colectivo. Así, el artículo 4o. establece que "Toda persona tiene derecho a un medio ambiente sano para su desarrollo y bienestar. El Estado garantizará el respeto a este derecho...".

38 De la Declaración de Río sobre el Medio Ambiente y el Desarrollo, del 14 de junio de 1992, se destacan por su aportación al robustecimiento legal del derecho humano a un medio ambiente sano, los siguientes fundamentos: 1 . El derecho del ser humano a una vida sana y productiva en relación directa y armónica con la naturaleza (principio 1); 2. La soberanía de los Estados sobre sus recursos naturales (principio 2); 3. El ejercicio equitativo del derecho al desarrollo, de tal forma que puedan suplirse las necesidades tanto de las generaciones presentes como futuras (principio 3), y 4. La aplicación del criterio de precaución en el sentido más amplio posible, cuando refiera de proteger al medio ambiente de cualquier daño grave o irreversible (principio 15).

39 El Protocolo de San Salvador del 17 de noviembre de 1988, fue el instrumento jurídico que estableció a través de su artículo 11 , apartados 1 y 2, el derecho humano a un medio ambiente sano a nivel región internacional:

"Artículo 11. Derecho a un medio ambiente sano.

1. Toda persona tiene derecho a vivir en un medio ambiente sano...

2. Los Estados partes promoverán la protección, preservación y mejoramiento del medio ambiente". 
A la par, y como corolario obligado, el principal ordenamiento legal federal en materia del medio ambiente acogió en su cuerpo normativo los efectos jurídicos propiciados por la incorporación constitucional de este derecho fundamental, lo que llevó a precisar también en su contenido el objetivo fundamental al que obedece el derecho humano a un medio ambiente sano. ${ }^{40}$

Por su parte, los tribunales internacionales y nacionales han hecho lo propio para el desarrollo del derecho al medio ambiente a través de sus pronunciamientos. Los sistemas europeo y americano, por ejemplo, han conocido de diversos juicios vinculados de manera directa o indirecta con el derecho humano al medio ambiente sano, lo que les ha permitido abonar mediante sus interpretaciones al alcance del fin primordial que se pretende alcanzar por medio de este derecho humano. ${ }^{41}$

El Tribunal Europeo, de forma particular, como precisa De Oliveira Mazzuolli, ha desarrollado interpretaciones encaminadas a establecer su interrelación con los diversos derechos humanos, como el de la vida, la privacidad y la propiedad. ${ }^{42}$ Es decir, se ha caracterizado por generar

40 El artículo 1o. de la Ley General del Equilibrio Ecológico y la Protección al Ambiente, del 28 de enero de 1988, fue modificado el 5 de noviembre de 2013, con la finalidad de incorporar los alcances jurídicos que la modificación constitucional en materia de derecho humano a un medio ambiente sano buscaba imprimir dentro del Estado mexicano:

"Artículo 1o. La presente Ley es reglamentaria de las disposiciones de la Constitución Política de los Estados Unidos Mexicanos que se refieren a la preservación y restauración del equilibrio ecológico, así como a la protección al ambiente, en el territorio nacional y las zonas sobre las que la nación ejerce su soberanía y jurisdicción. Sus disposiciones son de orden público e interés social y tienen por objeto propiciar el desarrollo sustentable y establecer las bases para:

I. Garantizar el derecho de toda persona a vivir en un medio ambiente sano para su desarrollo, salud y bienestar".

41 Para apreciar el progreso que el derecho humano a un medio ambiente sano ha tenido en los órganos jurisdiccionales internacionales, $c f r$. en el Tribunal Europeo de Derechos Humanos los casos: Powell y Rayner vs. Reino Unido, sentencia del 21 de febrero de 1990, aplicación 9310/81; López Ostra vs. España, sentencia del 9 de diciembre de 1994, aplicación 16798/90; Ana María Guerra y otros vs. Italia, sentencia del 19 de febrero de 1998, aplicaciones 116/1996/735/932; Tatar vs. Rumania, sentencia del 27 de enero 2009, aplicación 67021 /01; y en la Corte Interamericana de Derechos Humanos: comunidades indígenas mayas de Toledo vs. Belice, 12 de octubre de 2004; comunidad indígena Sawhoyamaxa. vs. Paraguay, sentencia del 29 de marzo, 2006, y comunidad de La Oroya vs. Perú, 5 de agosto de 2009.

42 Cfr. para profundizar sobre el papel del Tribunal Europeo de Derechos Humanos en materia de derecho humano al medio ambiente sano a De Oliveira Mazzuoli, Valerio,

Esta obra está bajo una Licencia Creative Commons

Atribución-NoComercial-SinDerivar 4.0 Internacional, IIJ-UNAM.

Boletín Mexicano de Derecho Comparado, núm. 150, pp. 1115-1147 
criterios que denotan la incidencia que el medio ambiente sano tiene en la consolidación de los demás derechos fundamentales por su inminente y recíproca vinculación.

La Corte Interamericana de Derechos Humanos al igual que su homóloga europea también ha enriquecido a este derecho humano estableciendo criterios donde se demuestra su innegable importancia para consumar eficazmente a otros derechos humanos. Sin embargo, como de nuevo señala Oliveira Mazzuolli, sus criterios se originan de problemáticas un tanto distintas, básicamente se presentan en atención a la desregulada explotación económica de los recursos naturales ${ }^{43}$ lo cual indudablemente le da un enfoque más colectivo que en el caso europeo. ${ }^{44}$

Independientemente de lo anterior, ambos órganos jurisdiccionales internacionales promueven en sus interpretaciones, criterios dirigidos, en mayor o menor intensidad, al señalar que la presencia de agentes de tipo contaminantes en el medio ambiente disminuyen su sanidad, lo que va en detrimento de la salud física o mental, de la privacidad y seguridad dentro de la propiedad, de la cultura y forma de vivir de las personas, entre otros aspectos más que procuran los distintos derechos humanos, lo cual les propicia una grave disminución en las condiciones de calidad de vida individual y colectiva, y donde el Estado es el agente principal para garantizar la tutela jurídica efectiva de la salud y el equilibrio ecológico. ${ }^{45}$

Acorde con lo expuesto, Orellana señala que

Además del reconocimiento de los vínculos entre derechos humanos y ambiente en instrumentos de derecho internacional, los mecanismos regionales de protección de los derechos humanos también han profundizado estos vínculos. Este desarrollo se ha manifestado en dos vertientes. Por una vía se ha identificado el contenido ambiental de ciertos derechos protegidos, como

"Protección jurídica del medio ambiente en la jurisprudencia de la Corte Interamericana de Derechos Humanos", Revista Internacional de Derechos Humanos, año V, núm. 5, enerodiciembre de 2015, p. 24.

43 De Oliveira Mazzuoli, Valerio, op. cit., p. 28.

44 Cfr. para denotar las diferencias comentadas los casos de Öneryildiz vs. Turquía, sentencia del 18 de junio 2002, aplicación 48939/99, del Tribunal Europeo de Derechos Humanos y del Pueblo Indígena Kichwa de Sarayaku vs. Ecuador, sentencia del 27 de junio de 2013, serie C, núm. 245, de la Corte Interamericana de Derechos Humanos.

45 Orellana, Marco, "Derechos humanos y ambiente: desafíos para el sistema interamericano de derechos humanos", Ozono Mío Revista de Derecho Ambiental, núm. 6, p. 293. 
el derecho a la vida, la integridad personal, la vida privada, y el acceso a la información. Por otra vía se han precisado las limitaciones permisibles al ejercicio de derechos por razones ambientales, incluyendo un análisis de necesidad, proporcionalidad, e interés público.

El Estado mexicano por medio de su tribunal constitucional, de igual manera, ha aportado al desarrollo de este derecho humano, ya que mediante diversos pronunciamientos se ha encargado de contribuir a la interpretación del propósito principal que dicho derecho fundamental persigue. Un ejemplo de lo anterior se aprecia en las sentencias constitucionales 192/2013, del 10 de julio de 2013, y 388/2008, del 29 de octubre de 2008.

En la primera, el tribunal constitucional mexicano precisa que la salvaguarda del derecho fundamental a un medio ambiente sano constituye una obligación que debe ser planteada como un objetivo legítimo del Estado mexicano, a fin de que todas las personas gocen de un medio ambiente que les permita su desarrollo y bienestar humano. ${ }^{46}$

Mientras que en el segundo pronunciamiento fija que la calidad del ambiente se procura mediante el aminoramiento del impacto ambiental causado por agentes contaminantes, pues con ello se brinda a los miembros de la sociedad el medio ambiente sano y adecuado que se requiere para proporcionar los satisfactores de salud, capacidad reproductiva y calidad de vida en general. ${ }^{47}$

Lo que el tribunal constitucional mexicano aporta mediante estos fallos al alcance del fin principal que el derecho humano a un medio ambiente sano detenta, desde una apreciación armónica de ambos, es un criterio que establece que para ejercer este derecho es imprescindible gozar de un entorno ambiental lo suficientemente salubre para realizar el desenvolvimiento adecuado de la vida individual y colectiva de las personas, y donde la figura del Estado debe ser la que lo garantice en toda su amplitud.

Esta contribución normativa y jurisdiccional se ve complementada con la aportación científica que la doctrina hace en relación con el alcance

46 Tesis 1a. CCCXXXII/2013 (10a.), Seminario Fudicial de la Federación y su Gaceta, Décima Época, t. I, noviembre de 2013, p. 531.

47 Tesis I.7o.A.599, Seminario Fudicial de la Federación y su Gaceta, Novena Época, t. XXVIII, diciembre de 2008, p. 1089.

Esta obra está bajo una Licencia Creative Commons

Atribución-NoComercial-SinDerivar 4.0 Internacional, IIJ-UNAM.

Boletín Mexicano de Derecho Comparado, núm. 150, pp. 1115-1147 
y significación de este derecho fundamental, lo que abona aún más a la representación de los parámetros legales que busca instaurar para lograr su cometido.

Por su parte, Rodríguez Beltrán señala que el derecho al medio ambiente sano ha sido concebido como fundamental para la supervivencia de la especie humana, pues parte del conjunto de condiciones básicas que rodean y circundan la vida del hombre como miembro de una comunidad y por las cuales es posible consumar su existencia biológica e individual, su desempeño normal y su desarrollo integral social.

Asimismo - indica el autor - la doctrina lo ha determinado como un derecho subjetivo y colectivo, a la vez, porque está ligado de manera inseparable a la calidad de vida y al derecho a la salud, no sólo de las generaciones presentes, sino también de las futuras, y donde para su ejercicio, la prevención y precaución del mismo juegan un papel decisivo por cuanto no se trata de reparar los daños ocasionados, sino de prevenirlos, ya que una vez acontecidos sus efectos casi siempre son de carácter irreversible. ${ }^{48}$

Ampliando aún más la importancia general que tiene el derecho a un medio ambiente sano, la doctrina científica, a través de Loperena Rota, apunta que "el medio ambiente adecuado no es un fruto del desarrollo social, sino un prius para su existencia", y agrega: "Es un derecho vinculado a la propia vida humana: donde hay medio ambiente adecuado hay seres humanos... El medio ambiente adecuado precede lógicamente al propio Derecho: sin medio ambiente adecuado no hay vida humana, no sociedad, ni Derecho". ${ }^{49}$

Fensterseifer, por su parte, señala que el derecho al medio ambiente sano ha sido consagrado como un derecho esencial por su calidad y cualidad vital para el desenvolvimiento humano digno presente y futuro, ya que el concepto actual de vida que hoy se desarrolla va más allá del concepto tradicionalista de lo estrictamente biológico, lo cual crea una dimensión existencial más plena donde la calidad del medio ambiente actúa como un elemento fundamental para el desarrollo del ser humano. ${ }^{50}$

48 Rodríguez Beltrán, Juan José, "Los derechos humanos y el medioambiente", Diakaion. Revista de Fundamentación Furídica, núm. XV, noviembre de 2016, pp. 71-78.

49 Loperena Rota, Demetrio, Los principios del derecho ambiental, Madrid, Civitas, 1998, p. 31 .

50 Fensterseifer, Tiago, Direitos fundamentais e proteção do ambiente. A dimensão ecológica da dignidade humana no marco juridico-constitucional do Estado socioambiental de direito, Porto Alegre, 
En ese mismo sentido, Anglés Hernández apunta que la protección del medio ambiente ha sido asumida de manera coincidente por la comunidad científica internacional y nacional de los Estados del orbe, en el sentido de precisarla como una premisa esencial para la existencia y preservación de la especie humana, donde se ha redimensionado la actuación humana para alcanzar el desarrollo anhelado por todos. ${ }^{51}$

Por último, Moyano Bonilla destaca que la importancia del derecho al medio ambiente sano radica en que todo ser vivo en el planeta - el hombre, los animales y las plantas - depende para subsistir de los bienes que conforman el medio ambiente, como el aire, el agua, tanto "el hombre, como los animales y las plantas, no pueden existir como entidad totalmente independiente y aislada, sino que dependen del ambiente, toda vez que requiere para subsistir, entre otras cosas, del aire, del agua, de una temperatura adecuada, etcétera. Por ello, la importancia que tiene su preservación".

$\mathrm{Y}$ añade:

La contaminación del ambiente se presenta en bienes que integran el patrimonio común de la humanidad y que, además, amenaza su supervivencia, razón por la cual ésta tiene interés en su protección, conservación y transmisión a las generaciones futuras, lo que obliga a los hombres y a los Estados a adoptar medidas para obtener tales fines, por tratarse de un interés común y superior. ${ }^{52}$

Es posible apreciar que los distintos impactos ambientales como el aumento e intensidad de la actividad industrial petrolera, junto con los proyectos complementarios a ésta, repercutirían de manera negativa en la calidad del medio ambiente, ya que la estabilidad de los ecosistemas se vería alterada por los agentes contaminantes que se producen comúnmen-

Livraria do Advogado Editora, 2008, p. 28. De igual manera, para ampliar sobre el contenido esencial del derecho humano al medio ambiente sano, cfr. Gaviao Filho, Anzio Pires, Direito fundamental ao ambiente, Porto Alegre, Livraria do Advogado Editora, 2005, pp. 35 y 39.

51 Anglés Hernández, Marisol, "Acciones colectivas en materia de protección ambiental, fallas de origen", Boletín Mexicano de Derecho Comparado, núm. 144, enero-diciembre de 2015 , pp. 900 y 901 .

52 Moyano Bonilla, César, "Derecho a un medio ambiente sano", Boletín Mexicano de Derecho Comparado, año XXVIII, núm. 82, enero-abril de 1995, pp. 231 y 239.

Esta obra está bajo una Licencia Creative Commons

Atribución-NoComercial-SinDerivar 4.0 Internacional, IIJ-UNAM.

Boletín Mexicano de Derecho Comparado, núm. 150, pp. 1115-1147 
te por esta actividad industrial, lo que indudablemente alteraría el bien y los valores jurídicos ${ }^{53}$ que el derecho humano a un medio ambiente sano procura, afectando con ello la calidad de vida individual y colectiva de las personas que habitan en las regiones de perfil hidrocarburífero.

Así, de acuerdo con los distintos criterios normativos, jurisdiccionales y doctrinales, el principal valor jurídico que el derecho humano al medio ambiente sano protege es la calidad integral del entorno ambiental que rodea al ser humano, a la colectividad, la cual debe ser lo suficientemente sana para desarrollarse adecuadamente en cada aspecto que integra su bienestar personal y social, por lo que cualquier daño o alteración negativa al mismo se podría considerar en perjuicio del goce y ejercicio de ese derecho fundamental.

Como se aprecia, la modificación constitucional de los hidrocarburos es, y ha generado, una proyección pública nacional y regional que se concentra preponderantemente en sustanciar y complementar el desarrollo de la nueva industria de los hidrocarburos con el objetivo principal de potencializar el impacto económico que se espera obtener con la misma en los sectores social, privado y gubernamental.

Lo anterior resulta hasta cierto punto apropiado dentro del contexto sobre el cual la reforma constitucional se desenvolvió, pues sin duda esas acciones fomentarían el auge económico que se pretende sustentar bajo la nueva forma constitucional de explotación del recurso natural hidrocarburífero. ${ }^{54}$ Sin embargo, es posible apreciar también que no solamente la

53 Moyano Bonilla precisa al aire, al agua, a la capa de ozono y a los demás recursos naturales, en general, como los bienes jurídicos tutelados por el derecho al medio ambiente sano, ya que se constituyen en el patrimonio común de la humanidad, tal y como se desprende de los distintos instrumentos jurídico internacionales, como la Carta de los Derechos y Deberes Económicos de los Estados, de 1972, la Convención de las Naciones Unidas sobre el Derecho del Mar, de 1982, o la Declaración de Río de Janeiro sobre el Medio Ambiente y el Desarrollo, de 1992, op. cit., pp. 234 y 235.

54 Jaime Cárdenas Gracia señala que de los objetivos planteados en la reforma constitucional, varios de ellos extraídos del sector empresarial nacional y transnacional, la meta principal era, y es, obtener "la máxima explotación de los recursos para optimizar el beneficio económico de las empresas, sin advertir, entre otras, las consecuencias medioambientales y de salud que traería consigo una reforma constitucional destinada casi exclusivamente a premiar la rentabilidad empresarial nacional y trasnacional", lo que, agrega el autor, "puede erigirse en el detonante de riesgos económicos, sociales y ambientales asociados al calentamiento global, cuyas consecuencias pueden ser devastadoras para nuestro país y el resto del mundo". Op. cit., pp. 23 y 45.

Esta obra está bajo una Licencia Creative Commons Atribución-NoComercial-SinDerivar 4.0 Internacional, IIJ-UNAM. Boletín Mexicano de Derecho Comparado, núm. 150, pp. 1115-1147 
intención oficial generaría la repercusión económica esperada, sino también otro tipo de repercusión, una de carácter jurídico social.

$\mathrm{Y}$ es que la introducción masiva de las actividades vinculadas directa e indirectamente a la explotación de hidrocarburos fomentarían una mayor generación de pasivos ambientales para las regiones petroleras, como la de Tamaulipas, lo que iría en detrimento de la garantía constitucional que se ha fijado a partir del esquema jurídico internacional en materia de medio ambiente.

Efectivamente, la proyección pública, en general, se encuentra ocupada principalmente en tratar de cumplir con los objetivos económicos planteados a través del cambio constitucional, lo que está abrumando y, en consecuencia, distrayendo la atención de otras coyunturas jurídicas que podrían presentarse como resultado simultáneo a su implementación, y que son igual de relevantes como la consecución económica planteada, ya que la afectación que se podría ocasionar sobre los ecosistemas de las regiones donde sobrevendrá el aumento en la explotación de hidrocarburos causaría una grave repercusión jurídica en su entorno social. ${ }^{55}$

\section{Gonalusiones}

Como se ha expuesto, a la par del posible efecto económico que se produciría por la dinámica de las actividades directas e indirectas vinculadas al desarrollo de la nueva industria de los hidrocarburos, también se podría dar otro posible efecto, uno que impactaría principalmente al sector social, que de no ser debidamente atendido podría reproducir un retroceso para el entorno regional más que un desarrollo.

La posibilidad de que la nueva industria de los hidrocarburos produzca una regresión para el sector social es igual de factible que la generación

55 Resulta conveniente mencionar que en la entidad federativa que se analizó como caso de estudio han sido licitados bajo el nuevo esquema constitucional de explotación de hidrocarburos nacionales dos proyectos terrestres y cuatro marítimos: el área contractual número 20, que abarca una superficie de $24 \mathrm{~km}$ e incluye al campo Ricos, ubicado en el municipio de Río Bravo; el área contractual número 1, que abarca una superficie de $11 \mathrm{~km}$ e incluye al campo Barcodón, situado en el municipio de Jiménez, y cuatro áreas en aguas profundas ubicadas frente a las costas de Tamaulipas. Licitaciones públicas CNH-R01L03/2015 y CNH-R01-L04/2015, publicadas en el Diario Oficial de la Federación, del 12 de mayo y 17 de diciembre de 2015, respectivamente.

Esta obra está bajo una Licencia Creative Commons

Atribución-NoComercial-SinDerivar 4.0 Internacional, IIJ-UNAM.

Boletín Mexicano de Derecho Comparado, núm. 150, pp. 1115-1147 
de un desarrollo económico, ya que las actividades propias de la industria y las complementarias que se han planeado para fomentar su establecimiento y desarrollo en los territorios con presencia de hidrocarburos favorecerían a su vez un entorno propicio para afectar el adecuado ejercicio de ciertos derechos fundamentales.

Las probables situaciones que se han vislumbrado conjuntamente con el escenario económico que la implementación operativa de la enmienda constitucional provocaría muestran la posibilidad de que se origine a la par un retroceso en diversos aspectos sociales, el cual partiría de la falta de un ejercicio jurídico adecuado de los derechos humanos involucrados con el desarrollo individual y colectivo, en el caso particular como el del medio ambiente.

Lo anterior daría como resultado que el bien colectivo que se pretende obtener con la reforma constitucional en materia energética a través del impacto que el crecimiento económico origine por el aumento en la explotación de los hidrocarburos nacionales fuera incompleto, pues conjuntamente se estaría mermando el goce adecuado de los bienes y valores jurídicos de orden social que los derechos fundamentales promueven, instauran y protegen; aquellos que junto con el bienestar económico constituyen el bien común colectivo en toda su extensión.

Lo anterior vuelve indispensable encontrar los medios que ayuden a equilibrar los posibles efectos económicos y sociales entre la población, para que el bien común colectivo integral que la propia Constitución mexicana persigue, tanto por medio de la explotación de los recursos naturales nacionales como por el adecuado ejercicio de los derechos humanos, se concretice en la mayor y mejor medida posible.

Uno de los medios que se proponen sería la modificación del cuadro legal del fondo presupuestario que se creó por el Estado mexicano, para atender precisamente lo concerniente al tema ambiental de las regiones donde se implementará de manera intensiva la explotación de hidrocarburos, el denominado Fondo para Entidades Federativas y Municipios Productores de Hidrocarburos, ya que su orientación legal es dirigida a atender el daño ocasionado por la explotación de hidrocarburos y no para prevenirlo.

En efecto, de acuerdo con los lineamientos regulatorios establecidos para dicho fondo, los recursos económicos que se destinen para atender la interacción que se presente entre la explotación de hidrocarburos y el me- 
dio ambiente serán exclusivamente para generar proyectos de infraestructura que ayuden a resarcir las afectaciones ambientales y sociales que se ocasionen por la actividad industrial, lo cual resulta contrario a las obligaciones estatales que establece el derecho humano al medio ambiente sano a través de sus diversos principios, como lo son el de anticipar, prevenir y atacar las causas que puedan producir degradación ambiental.

Por tanto, una primera propuesta de orden jurídico con repercusión tangible en el ámbito regional —entidades federativas y municipios - sería la de modificar la Ley de Ingresos sobre Hidrocarburos junto con las reglas de operación que se establecieron para la aplicación de sus recursos, en el sentido de ampliar el enfoque que el Estado mexicano le imprimió; esto es, que no sólo sea de naturaleza resarcitiva, sino también, y preferentemente, de esencia preventiva.

La anterior traería consigo que los recursos económicos destinados para el entorno ecológico regional sean encauzados para desarrollar programas e infraestructura que ayuden preponderantemente a prevenir el daño ambiental que se considera ocurrirá con la implementación de la nueva industria de los hidrocarburos que se configuró constitucionalmente para obtener la seguridad energética nacional, y para que consecuentemente, y de acuerdo con los alcances que el derecho humano al medio ambiente sano persigue, se evite una afectación en las condiciones de vida de las personas situadas en las extensas regiones de explotación.

\section{FUentes CONSULTADAS}

Aguilera Gómez, Manuel, El petróleo mexicano. Conflicto, esperanza y frustración, México, M. A. Porrúa-UNAM, 2015.

AlPizar VAlLEJO, Rodrigo, "El consorcio o la asociación industrial como una estrategia de oportunidad de la industria nacional dentro de la reforma energética del país", en OROPEZA GARCíA, Arturo (coord.), Reforma energética y desarrollo industrial. Un compromiso inaplazable, México, UNAM, Instituto de Investigaciones Jurídicas, 2015.

Álvarez Molina, Marianella, "Los alcances del derecho a un ambiente sano y ecológicamente equilibrado en Costa Rica", Foro Constitucional Iberoamericano, año III, núm. 9, enero-abril de 2005. 
ANAYA MERchant, Luis, Historia económica regional, Ciudad Victoria, Universidad Autónoma de Tamaulipas, vol. IV, 2013, colección Lecturas Históricas de Tamaulipas.

Anglés Hernández, Marisol, "Acciones colectivas en materia de protección ambiental. Fallas de origen", Boletin Mexicano de Derecho Comparado, núm. 144, enero-diciembre de 2015.

BARCON PALOMAR, Santiago, “¿Energía o anarquía en materia energética? Cómo aprovechar la reforma energética en materia industrial”, en Oropeza García, Arturo (coord.), Reforma energética y desarrollo industrial. Un compromiso inaplazable, México, UNAM, Instituto de Investigaciones Jurídicas, 2015.

Benglio Valdez, Mariana, "Derecho humano a un medio ambiente sano", Sexto certamen de ensayo sobre derechos humanos. El derecho humano a un medio ambiente sano, México, Comisión de Derechos Humanos del Estado de México, 2003.

CÁRDENAS GRACIA, Jaime, Crítica a la reforma constitucional energética 2013, México, UNAM, Instituto de Investigaciones Jurídicas, 2014.

Castán Tobeñas, José, Los derechos del hombre, Madrid, Ralos, 1985.

Clave AlmeidA, Eduardo, "La riqueza del archivo histórico de Petróleos Mexicanos", Revista de Fuentes e Investigación, vol. 23, enero-junio de 2005.

De Oliveira Mazzuoli, Valerio, "Protección jurídica del medio ambiente en la jurisprudencia de la Corte Interamericana de Derechos Humanos", Revista Internacional de Derechos Humanos, año V, núm. 5, enero-diciembre de 2015.

FERnÁndez SEgado, Francisco, "La teoría jurídica de los derecho fundamentales en el Tribunal Constitucional", Revista Española de Derecho Constitucional, año 13, núm. 39, septiembre-diciembre de 1993.

Fensterseifer, Tiago, Direitos fundamentais e proteção do ambiente. A dimensão ecológica da dignidade humana no marco juridico-constitucional do Estado socioambiental de direito, Porto Alegre, Livraria do Advogado Editora, 2008.

García Herrera, Miguel Ángel, "Principios generales de la tutela de los derechos y libertades en la Constitución española", Revista de la Facultad de Derecho de la Universidad Complutense, núm. 2, 1979.

García Rivera, Enoc Alejandro, "La nueva enmienda constitucional de los hidrocarburos y su vinculación con las finanzas municipales", en ANGLÉs HeRnánDez, Marisol (coord.), Reforma en materia de hidrocarbu- 
Esta revista forma parte del acervo de la Biblioteca Jurídica Virtual del Instituto de Investigaciones Jurídicas de la UNAM

ros. Análisis jurídicos, sociales y ambientales en prospectiva, México, UNAMUAT, 2017.

, "La renovada regulación constitucional de los hidrocarburos nacionales", Revista Mexicana de Derecho Constitucional, núm. 33, julio-diciembre de 2015.

Gaviao Filho, Anzio Pires, Direito fundamental ao ambiente, Porto Alegre, Livraria do Advogado Editora, 2005.

Loperena Rota, Demetrio, Los principios del derecho ambiental, Madrid, Civitas, 1998.

LOREnzo Rodríguez-Armas, Magdalena, Análisis del contenido esencial de los derechos fundamentales, Granada, Comares, 1966.

Morales Ramírez, Dionicio, "Evaluación del impacto social en las actividades de extracción del gas shale y el boom-bust cycle", en ROUX, Ruth (coord.), Los hidrocarburos en el noreste de México. Una mirada multidisciplinaria, Ciudad Victoria, Colegio Tamaulipas-UAT, 2016.

Moyano Bonilla, César, "Derecho a un medio ambiente sano", Boletín Mexicano de Derecho Comparado, año XXVIII, núm. 82, enero-abril de 1995.

Muñoz, Virgilio y Acuña Borbolla, Manuel, Nuestra Constitución. Historia y valores de una nación, México, Fondo de Cultura Económica, 2001.

Nogueira Alcalá, Humberto, Teoría y dogmática de los derechos fundamentales, México, UNAM, Instituto de Investigaciones Jurídicas, 2003.

ORTíNEZ BRITO, Oscar et al., "La restauración de suelos contaminados con hidrocarburos en México", Gaceta Ecológica, núm. 69, octubre-diciembre de 2003.

Orellana, Marco, "Derechos humanos y ambiente: desafíos para el sistema interamericano de derechos humanos", Ozono Mío. Revista de Derecho Ambiental, núm. 6.

Ortuño Arzate, Salvador, El mundo del petróleo, México, Fondo de Cultura Económica, 2009.

Peces-BARbA, Gregorio, Derechos fundamentales, Madrid, Universidad Complutense de Madrid, 1983.

PONS-JIMÉNEZ, Mirna et al., "Extracción de hidrocarburos y compuestos derivados del petróleo en suelos con características físicas y químicas diferentes", Revista Universidad y Ciencia, vol. XXVII, núm.1, abril de 2011. 
Esta revista forma parte del acervo de la Biblioteca Jurídica Virtual del Instituto de Investigaciones Jurídicas de la UNAM

Rivera Castro, José, "La expropiación petrolera. Raíces históricas y respuesta de los empresarios extranjeros", Revista Casa del Tiempo, vol. I, IV época, núm. 8, junio de 2008.

RoBerts, Paul, El fin del petróleo, Barcelona, Ediciones B, 2010.

RoDríguez BELTRÁn, Juan José, "Los derechos humanos y el medioambiente", Diakaion. Revista de Fundamentación Furídica, núm. XV, noviembre 2016.

Rojas AMANDI, Víctor Manuel, "El derecho internacional público del medio ambiente al inicio del siglo XXI", Anuario Mexicano de Derecho Internacional, vol. II, enero-diciembre de 2002.

Roux, Ruth, Impactos sociales de la extracción de gas lutitas en Tamaulipas, México, Plaza y Valdez-UAT, 2016.

VIDAL LEÓn, Christian, "El derecho al medio ambiente sano y su evolución internacional. Logros y retos", Sexto certamen de ensayo sobre derechos humanos. El derecho humano a un medio ambiente sano, México, Comisión de Derechos Humanos del Estado de México, 2003.

Fecha de recepción: 02 de septiembre de 2016

Fecha de aceptación: 12 de marzo 2017

Esta obra está bajo una Licencia Creative Commons Atribución-NoComercial-SinDerivar 4.0 Internacional, IIJ-UNAM. Boletín Mexicano de Derecho Comparado, núm. 150, pp. 1115-1147 